\title{
ISSO VAI DAR SAMBA: A PERSPECTIVA AFROGENICA E DECOLONIAL PELA LINGUÍSTICA APLICADA
}

\author{
"Isso vai dar samba": the afrogenic and decolonial perspective through applied Linguistics \\ "Isso vai dar samba"2: la perspectiva afrogénica y decolonial por la Linguística Aplicada
}

Doris Cristina Vicente da Silva Matos ${ }^{3}$
Universidade Federal de Sergipe

Gabriela Rodrigues Botelho
Universidade Federal de Sergipe

\section{RESUMO}

Este artigo, situado na área da Linguística Aplicada, analisa os sambas-enredo de 2019 das escolas de samba cariocas Vila Isabel e Mangueira. A análise está afroepistemologicamente baseada na proposta do giro decolonial, especialmente nos conceitos de colonialidade do poder, do saber e do ser, de maneira que a perspectiva afrogênica possa ser um caminho para a construção de saberes desde dentro, suleados. Os resultados classificam os sambas-enredo em categorias opostas: a eurogênica e a afrogênica, indicando que as versões das narrativas contadas podem produzir discursos de silenciamento ou visibilizar o passado histórico através da reafirmação das identidades étnico-raciais.

Palavras-chave: Linguística Aplicada. Decolonialidade, sulear. Perspectiva afrogênica. Samba-enredo

\section{ABSTRACT}

The present article, built upon Applied Linguistics, is a research of the 2019 samba-plots from Rio de Janeiro samba schools Vila Isabel and Mangueira. The research is afro-epistemologically based on the decolonial spin paradigm, specially in the concepts of coloniality of power, of knowing and of being, in a sense that afrogenic perspective might be a way to build up knowings from inside out. Results identify samba-plots in two opposite categories: eurogenic and afrogenic, which gives the understanding that different narrative versions can silence or make visible the historical past through reaffirming racial-ethnic identities.

Keywords: Applied Linguistics. Decoloniality. Southing. Afrogenic perspective. Samba-Plots.

\section{RESUMEN}

Este artículo, ubicado en el área de la Lingüistica Aplicada, analiza los sambas-enredo de 2019 de las escuelas de samba Vila Isabel y Mangueira. El análisis está afroepistemológicamente basado en el giro decolonial, especialmente en los conceptos de colonialidad del poder, del saber y del ser, de modo que la perspectiva afrogénica pueda ser un camino para la construcción de saberes desde dentro, sureados. Los resultados clasifican los sambas-enredo en categorías opuestas: la eurogénica y la afrogénica, sosteniendo que las narrativas pueden silenciar o visibilizar el pasado histórico a través de la reafirmación de las identidades étnico-raciales.

Palabras clave: Lingüística aplicada. Decolonialidad. Surear. Perspectiva Afrogénica. Samba-Enredo.

\footnotetext{
${ }^{1}$ Expression in Portuguese used in this article with the meaning of something that goes well, with positive response.

${ }^{2}$ Expresión en portugués utilizada en este artículo con el significado de algo que va a salir bien, con respuesta positiva.

${ }^{3}$ Professora associada da Universidade Federal de Sergipe. Possui Doutorado em Língua e Cultura pela Universidade Federal da Bahia, Mestrado em Letras (Linguistica Aplicada ao Ensino/ Aprendizagem de Espanhol LE) pela Universidade Federal Fluminense, Especialização em Língua Espanhola Instrumental para Leitura pela Universidade do Estado do Rio de Janeiro e Graduação em Letras (Português/ Espanhol) pela Universidade Federal Fluminense. Email: profadoris_ufs@yahoo.com.br

${ }^{4}$ Mestranda do Programa de Pós-Graduação em Letras da Universidade Federal de Sergipe, Agência de fomento FAPITEC/SE. Possui Especialização em Multiletramentos na Educação Linguística e Literária em Espanhol pela Universidade Federal de Sergipe e Graduação em Letras (Espanhol) pela Universidade Estadual de Londrina. Email: gabibottelho@hotmail.com
} 
Recebido em: dezembro 2019

Aceito em: dezembro 2019

DOI: $10.26512 /$ les.v21i1.28457

\section{INTRODUÇÃO}

Este artigo tem como objetivo analisar os sambas-enredo de 2019 das escolas de samba cariocas Vila Isabel e Mangueira, escolhidos por apresentarem a temática da história colonial do Brasil. Para tanto, nos situamos no âmbito da Linguística Aplicada, que visa buscar inteligibilidades no meio social através da linguagem (MOITA LOPES, 2006). Assim, nos fundamentamos na proposta decolonial que pressupõe um giro ao encontro das vozes do Sul, como uma forma de conhecimento desde dentro. Nos pautamos também, nos conceitos de perspectiva eurogênica e afrogênica, como categorias de análise das respectivas letras de samba.

Consideramos que dentre as semelhanças históricas de contextos como a América Latina, marcados pela colonização, o processo de colonialidade seja um dos traços que delineiam as relações sociais e se manifestam pela linguagem. Entendemos a colonialidade, como a manutenção da lógica colonial que hierarquiza e organiza as ex-colônias, e, por conseguinte, mantem uma relação subalternizada diante dos países historicamente colonizadores, propagando essa lógica de subalternização nas suas próprias esferas sociais.

Ilustramos essa semelhança com três fatos que são abordados nos sambas-enredos e exemplificamos como os discursos de colonialidade se aproximam em diferentes ex-colônias. $\mathrm{O}$ primeiro ponto de aproximação entre contextos colonizados na América Latina é marcado pela identidade nacional, considerando-a uma herança europeia e negando as influências africanas e dos povos originários, para exemplificar, focamos no caso do samba no Brasil e do tango na Argentina. O segundo ponto de destaque nos sambas-enredo são as conquistas políticas, das quais destacamos a abolição da escravatura, exaltada como um feito europeu, desconsiderando as lutas locais, ocorridas, por exemplo, no Brasil e Peru. No terceiro ponto, é abordada a participação das mulheres e sobretudo das mulheres negras, que raramente são mencionadas como símbolo nacional, apesar de seus grandes feitos, para tanto nos pautamos nos países já mencionados: Brasil, Argentina e Peru.

Dividimos o texto em três partes: na primeira, demonstramos como a Linguística Aplicada se insere nas discussões decoloniais e apresentamos os conceitos que direcionam nossa análise. $\mathrm{Na}$ segunda parte, discutimos como a decolonialidade se faz presente na linguagem a partir da perspectiva afrogênica; debatemos a importância de se pensar conceitos que abrangem diferentes visões de mundo; fazemos uma recapitulação sobre o samba no Brasil e sobre como a colonialidade se faz 
presente em contextos historicamente colonizados. Na terceira seção, apresentamos a análise das letras dos sambas-enredo e por fim nossas conclusões.

\section{A Linguística APLiCADA E O GIRO DECOLONIAL}

A Linguística Aplicada (LA) tem se mostrado um campo dinâmico de investigação sobre a linguagem. Após as viradas linguística, somática e performática, sua vertente transgressiva (PENNYCOOK, 2006) tem buscado romper fronteiras epistemológicas para problematizar a linguagem, e assim, entender como o uso da língua influencia e reflete a sociedade. Por isso, a LA acompanha as mudanças no campo das ciências sociais que pretende entender os sujeitos e identidades que emergem no mundo contemporâneo, e é com base nesses sujeitos, até então silenciados, que apoia seus estudos. Segundo Moita Lopes (2006, p. 102):

Essa visão parece crucial em áreas como a LA, que têm como objetivo fundamental a problematização da vida social, na intensão de compreender as práticas sociais nas quais a linguagem tem papel crucial. Só podemos contribuir se considerarmos as visões de significado, inclusive aqueles relativos à pesquisa, como lugares de poder e conflito, que refletem os preconceitos, valores, projetos políticos e interesses daqueles que se comprometem a construção do significado e do conhecimento.

Pensar a investigação sobre linguagem por outros pontos de vista, que não do sujeito hegemônico, leva a LA a se posicionar como Kleiman (2013, p. 40), "Venho trazer outras vozes latino-americanas, a fim de "sulear" (orientar para o Sul) o debate e questionar a hegemonia ocidental do Norte, ainda imperante na definição dos nossos problemas de pesquisa". A autora se baseia nas concepções de norte global, caracterizado pelos países economicamente mais desenvolvidos e que atuaram historicamente como colonizadores (independentemente de estarem localizados no norte geográfico); e os países do sul global, tidos como subdesenvolvidos e que sofreram o processo de colonização principalmente na América Latina, África e Ásia, mas, também países ou regiões consideradas menos desenvolvidas ainda que estejam em zonas privilegiadas do norte geográfico. De acordo com Silva Júnior e Matos:

Quem primeiro fez uso do termo "sulear" e o cunhou, foi o físico brasileiro Marcio D’Olne Campos (1991) em contraposição ao caráter ideológico do vocábulo "nortear" e às representações advindas da relação imposta, injustamente, entre Norte-Sul, colocando o sul em uma posição inferior e/ou de desvantagem (SILVA JÚNIOR; MATOS, 2019, p. 104). 
Assim, ao sulear, em vez de orientar para o norte, as pesquisas em LA e também este artigo, buscam ouvir as demandas investigativas reivindicadas por esses sujeitos, que já não são vistos como objeto de investigação, mas como agentes sociais. Nesse contexto, as pautas do Programa Modernidade/Colonialidade (PM/C) evidenciadas em Escobar (2003), se destacam nos estudos da LA, já que confluem para o pensamento do Sul para o Sul. Segundo Kleiman (2013) a dimensão ética da LA está contemplada no PM/C na medida em que reivindica as histórias locais, não tem uma visão etnocida e não se prende a verdades únicas. O Programa discute os processos de colonialidade, e suas implicações no mundo atual, sendo as sociedades do sul global seu principal foco. Os teóricos do programa defendem que as categorias usadas para definir a modernidade ao mesmo tempo delineiam a coloniadade, ou seja, não mais o colonialismo, mas, os processos de construção social herdados do período colonial, portanto:

La colonialidad es uno de los elementos constitutivos y específicos del patrón mundial de poder capitalista. Se funda en la imposición de una clasificación racial/étnica de la población del mundo como piedra angular de dicho patrón de poder, y opera en cada uno de los planos, ámbitos y dimensiones, materiales y subjetivas, de la existencia cotidiana y a escala social. Se origina y mundializa a partir de América (QUIJANO, 2007, p. 93).

Segundo Escobar (2003, p. 61) "Las conclusiones principales son, primero, que la unidad analítica propia para el análisis de la modernidad es la modernidad/colonialidad —en suma, no hay modernidad sin colonialidad, siendo esta última constitutiva de la primera." Assim, a organização econômica, social, as diferenças raciais, de gênero, culturais e toda estrutura do pensamento moderno compreende formas de colonialidade. Segundo o PM/C, há quatro eixos que mantêm os processos de colonialidade: o eixo do poder, do ser, do saber e o da natureza. A colonialidade do poder é entendida como:

El hecho de que las categorías, que identifican lugares y papeles en las relaciones de poder, tengan la pretensión de ser simplemente nombres de fenómenos "naturales", tengan o no alguna referencia real en la naturaleza, es una indicación muy eficaz de que el poder, todo poder, requiere de ese mecanismo subjetivo para su reproducción (QUIJANO, 2007, p. 118).

Ao contestar a naturalização das categorias sociais trazidas para as Américas através da colonização, Quijano (2007) demonstra o papel desses elementos na hierarquização do poder para forjar um mecanismo que logo seria assimilado e desenvolvido pelo capitalismo no mundo. A colonialidade do poder é usada pelos colonizadores como forma de controle dos colonizados. Para o autor, esse mecanismo não poderia funcionar sem a visão eurocêntrica de que há humanos inferiores 
e superiores; racionais e irracionais; primitivos e civilizados; tradicionais e modernos; pois é essa concepção binária que garante a naturalização das categorias.

A partir da possibilidade de existência de seres superiores e inferiores é que se estabelece a colonialidade do ser. De acordo com Maldonado Torres (2007), "El surgimiento del concepto “colonialidad del ser" responde, pues, a la necesidad de aclarar la pregunta sobre los efectos de la colonialidad en la experiencia vivida, y no sólo en la mente de sujetos subalternos." Para o autor, os efeitos aparecem quando o humano já não pode reclamar sua autonomia, quando a servidão, a indiferença, a racialização e a morte já não podem ser confrontadas, restando a invisibilidade e desumanização, o não ser ontológico. Essa lógica de existência é engendrada na América a partir da colonização e segue como mecanismo de manutenção das relações de poder. Os quatro eixos da colonialidade podem ser encontrados nas mais diversas manifestações culturais e sociais, inclusive através da linguagem como vemos nesse artigo.

O binarismo estabelecido durante a colonização se estende às culturas, classificando o conhecimento do colonizador como válido e do colonizado como não válido. Desse modo, o desenvolvimento intelectual nos países colonizados ocorre com base na cosmovisão e métodos europeus, negando tudo que já havia de saber local, a esse processo o PM/C denomina colonialidade do saber. Por isso, Castro Gomes (2007), argumenta que o olhar colonial obedece um modelo epistêmico que continua sendo reproduzido em especial pela universidade, tanto em seu pensamento como em sua organização, garantindo a manutenção da colonialidade do poder, do ser, da natureza e nesse caso, principalmente do saber.

O eixo da natureza ou colonialidade cosmogônica, também é resultado da cosmovisão binária eurocêntrica, que ao separar a natureza e a sociedade, impossibilita a coexistência entre ambas. Para Walsh (2012), na visão dos povos originários e afrodescendentes a mãe natureza ordena o sentido do universo, da vida, dos conhecimentos, dos territórios, da história, do corpo, da mente, da espiritualidade e existência. Portanto, negar essa relação em detrimento do controle e do poder individual é uma forma de acabar com a base de vida dos povos ancestrais.

Aos quatro modos de colonialidade, Veronelli (2015) apresenta um quinto, a colonialidade da linguagem, como um quadro teórico para analisar relações linguísticas que acompanham a colonialidade do poder. Para a autora, a colonialidade da linguagem:

Es un aspecto del proceso de deshumanización de las poblaciones colonizadascolonializadas a través de la racialización. El problema que plantea la colonialidad del lenguaje es el problema de la relación raza/lenguaje. Dado que la racialización es inseparable de la apropiación y reducción eurocéntricas del universo de las poblaciones colonizadas, la relación raza/lenguaje es practicada dentro de una filosofía, una ideología y política eurocéntricas que incluyen una política lingüística. 
Desde dentro, el enorme aparato epistémico-ideológico de la modernidad permite a la imaginación colonial presuponer a los colonizados-colonializados como seres menos-que-humanos, expresiva y lingüísticamente (VERONELLI, 2015, p. 48).

$\mathrm{O} \mathrm{PM} / \mathrm{C}$ pretende, a partir do giro decolonial, desvelar as relações e construções sociais que perpetuam os modos de colonialidade (poder, ser, saber e natureza) e aqui, acrescentamos o da colonialidade da linguagem, como uma forma de ressignificar esses processos. Sob uma ótica do Sul, busca-se reconhecer e valorizar os saberes locais, bem como a cultura e a cosmovisão desses povos e entendemos que assim será possível melhor compreender tais sociedades. É a partir da concepção de que os processos de colonialidade permanecem, que dentro da LA os estudos se preocupam em entender tais relações. Por isso, a necessidade de considerar outros campos de estudo como a antropologia, a literatura e a filosofia, no sentido de compreender a sociedade que utiliza a língua e constrói continuamente a linguagem. Pesquisar questões que abrangem realidades da América Latina e, consequentemente do Brasil, como o processo de colonialidade, é uma forma de crítica e reflexão a esse processo e é também uma forma de exercitar a decolonialidade.

\section{PERSPECTIVA AFROGÊNICA COMO FORMA DE DECOLONIALIDADE E O SAMBA}

O exercício de decolonialidade implica entender que as regiões colonizadas sempre foram e continuam diversas. Embora os modos de colonialidade, seguindo o pensamento europeu, tenha homogeneizado essas regiões como forma de silenciamento e dominação, um olhar de dentro, permitirá ver a diversidade dos povos originários e afrodescendentes que compõe essas regiões. A perspectiva afrogênica vislumbra o estudo da cultura afrodiaspórica a partir dos próprios afrodescendentes, suas prioridades, experiências, interesses, articulações e interpretações, como afirma Walker (2018). Assim, não se contrapõe à categoria eurocêntrica, pois o objetivo não é sobrepor visões de mundo, mas, se coloca em igualdade à categoria eurogênica e as demais formas de ser, saber e pensar o mundo. Portanto, reflete o protagonismo das pessoas negras nas sociedades às quais são pertencentes independente da nacionalidade e das mais variadas formas. Em palavras de García (2012, p. 82 apud OSHAI, 2015, p. 255):

A categoria afrogênica foi criada por Walker e se contrapõe à categoria "eurogênicae, remete a aspectos de interesse e a construções teóricas e metodológicas, dentre outras, elaboradas pelas(os) próprias(os) africanas(os) e afrodescendentes em contraposição ao conhecimento tido como morto, construído por terceiros a fim de desqualificar "as inteligências históricas das diversas civilizações africanas sequestradas e transladadas a diferentes lugares [das] América[s] pela via do comércio de africanos escravizados". 
O esforço de Walker para cunhar um termo que abrangesse a forma de pensar o mundo das pessoas negras, converge com outros intelectuais que, a partir de suas pesquisas, demonstram como suas experiências não se encaixam nas narrativas eurogênicas. O filósofo brasileiro Renato Nogueira propõe o termo afroperspectividade, que como Walker, pretende pensar a experiência africana no mundo não somente a partir da diáspora, mas inclusive antes dela. Segundo Noguera (2011, p. 9) “A afroperspectividade consiste numa série de perspectivas de matriz africana.” Para o autor, o próprio samba seria uma forma de cosmovisão afro-brasileira.

$\mathrm{Na}$ literatura, Conceição Evaristo cunha o termo escrevivência como forma de classificar a escrita de mulheres negras relacionando a sua percepção de mundo entrelaçada à memória da escravidão que ainda marca as relações humanas no Brasil. Em palavras da autora "A nossa escrevivência não é para adormecer os da casa-grande, e sim para incomodá-los em seus sonos injustos. ${ }^{5}$ " Para Conceição, a literatura de mulheres negras é uma forma de ampliar seus espaços de atuação como agentes sociais, relacionando essas mulheres não mais à servidão, trabalhos domésticos ou cuidado dos filhos das classes abastadas, mas à reflexão, às reivindicações e denúncias de injustiças sofridas historicamente.

Entre os estudos decoloniais no Brasil, o professor Bernardino-Costa pensa a decolonialidade a partir de uma perspectiva negra, e, juntamente com Grosfoguel, se remetem aos intelectuais (ativistas, professores (as), escritores (as), pensadores (as), para além da academia) que fazem de seus trabalhos, estudos e ações um combate à colonialidade do poder, do ser, do saber e da natureza (BERNARDINO-COSTA; GROSFOGUEL, 2016). Podemos entender que para os autores esses (as) intelectuais também protagonizam o esforço para alcançar a decolonialidade no Brasil, pois, em outros termos, mas com a mesma intensão que o PM/C desvelam e combatem o sistema de poder colonial.

A partir dos conceitos apresentados, notamos a confluência entre os teóricos em problematizar suas respectivas áreas de pensamento, fundamentando-se em conhecimentos não eurocentrados, portanto, podendo ser entendidos como decoloniais, na medida em que contestam a construção do ser e do saber que fazem, para combater a colonialidade do poder. A busca por novos conceitos é importante, pois reflete o entendimento de mundo de negros e negras brasileiros (as) que não necessariamente converge com o entendimento hegemônico eurogênico. Por isso, nesse estudo da linguagem, com base na LA, nos valemos da perspectiva afrogênica para analisar como o samba enquanto expressão artística pode desvelar resquícios de colonialidade e possíveis discursos decoloniais.

\footnotetext{
${ }^{5}$ Entrevista concedida em setembro de 2017. Disponível: https://www.youtube.com/watch?v=4EwKXpTIBhE. Acesso 19 nov. 2019
} 
O samba, sendo uma arte musical, surge inicialmente como forma de expressão cultural e cosmovisão dos afrodescendentes e afro-brasileiros. Proveniente da palavra semba do tronco africano de línguas banto, tem sua origem nos ritmos de lundus, jongos ou mais genericamente batucadas existentes no Brasil do início do século XX. Abreu (1996), destaca em sua tese sobre a festa do Divino, que nesse período não havia registro da palavra samba. A nomenclatura mais conhecida era batuque, denominação segundo a autora dada pelos órgãos de repressão, jornalistas e viajantes quando se referiam a música e dança dos negros e negras no Rio de Janeiro e que lembrava as manifestações artísticas de Angola e outros países da África.

Em sua tese sobre a constituição do carnaval no Rio de Janeiro, Brasil (2016), destaca como essa forma de expressão cultural foi uma experiência importante e mobilizadora de negociações entre autoridades e as pessoas negras, em busca de cidadania, nesse contexto de pós-abolição. O autor demonstra como a repressão e a violência eram constantes em relação às agremiações, principalmente as que mantinham tradições africanas. Em um trecho da tese, Brasil (2016, p. 37) enumera as muitas exigências da polícia para conceder licença para desfile aos grupos carnavalescos majoritariamente compostos por negros e negras e destaca de uma de suas fontes que mesmo após a agremiação cumprir todas as exigências: “[...] o chefe de polícia havia decidido "proibir a exibição desses cordões de indivíduos fantasiados de índios, os quais são, quase sempre, os promotores de desordens e de acidentes na via pública".

A explicação do autor para tal proibição era de que essa fantasia denominada de índio na verdade representava rituais africanos e lembrava hábitos dos nossos povos originários, por isso a nomenclatura. É importante ressaltar essa passagem para marcar como tudo que se aproximava da cultura africana ou dos povos originários sofria alguma retaliação, e embora houvesse resistência, como houve nesse caso, muitas práticas do carnaval foram se perdendo com o tempo e dando espaço a costumes mais aceitos pelos componentes brancos da sociedade.

Esse tipo de repressão era comum no início do século XX, período no qual se formavam os Estados-Nações e principalmente nas Américas havia uma ânsia pelo moderno (tradição europeia) e desprezo pelo não moderno (tradição dos povos originários e africanos). Os Estados em formação queriam construir sua identidade com bases modernas e para isso escondiam e negavam tudo que não correspondesse a Europa. No Brasil, como vimos, o samba era uma forma de incluir e limitar a população que ainda conservava suas raízes africanas. Após a assimilação da arte pela elite carioca e negociações entre classes, o samba como fruto de mestiçagem se constituiu como identidade nacional, ora proclamando a história oficial, ora reivindicado espaço aos demais protagonistas da construção da identidade brasileira. Em outros países da América Latina o processo de colonialidade foi bastante semelhante. 
$\mathrm{Na}$ Argentina, a história do tango, também exemplo de identidade nacional, teve suas raízes africanas negadas, sendo constantemente lembrado como uma herança dos imigrantes italianos. No entanto, autores como Molina e López (2018) defendem que na segunda metade do século XVIII no território da atual Argentina, já havia registro de bailes africanos, que originaram comunidades africanas organizadas. Os bailes eram realizados em ranchos ou campos denominados tambo ou tango. Nesses bailes, também há registo da dança semba, chamada umbigada e, posteriormente, samba no Brasil. Segundo os autores, os bailes africanos eram mal vistos pelas autoridades locais, por serem considerados uma ofensa a Deus, por supostamente serem financiados por roubos ou por serem uma forma de organização entre os negros e negras. Entretanto, recebiam cerca de duas mil pessoas, inclusive brancos, sendo mais tarde considerado um símbolo nacional, para Molina e López (2018, p. 139):

O "tango," que como vimos era o lugar onde se realizavam festas e bailes de africanas, africanos e afrodescendentes, foi se transformando em uma das músicas mais representativas dos argentinos em geral. Com a contribuição dos imigrantes europeus convidados pelo governo para branquear o país, e que chegaram massivamente no final do século XIX e começo do XX, o tango também foi se "branqueando" (e como tudo feito por afrodescendentes, se foi ocultando e negando), transformando-se em uma dança de casais e de salão.

O apagamento das contribuições dos afrodescendentes e dos povos originários para a construção das Américas, é explicado pelo PM/C devido a estrutura da colonialidade se centrar na divisão racial. Para o programa, a hierarquia racial não é fruto da colonização e sim base dela. Por isso, a necessidade de ressaltar os feitos europeus como símbolo de superioridade e invisibilizar as ações dos outros povos, essa lógica foi e continua sendo aplicada de diversas formas e um bom exemplo é o discurso sobre a abolição da escravatura. Por muito tempo no Brasil, tal feito foi relacionado à ação da princesa Isabel em assinar a Lei Áurea, porém, é sabido que mais do que a bondade da princesa, a conjuntura internacional da época e as muitas rebeliões de escravizados entre outras ações em busca da liberdade, faziam do sistema escravista algo insustentável. A partir de uma visão decolonial, hoje visibilizamos os nomes de negros e negras que lutaram para serem livres e escreverem essa história.

O Peru, que assim como o Brasil sofreu e sofre os efeitos da colonialidade, um processo semelhante ocorreu ao consolidar o discurso sobre a abolição. Lobatón e Julca (2018), afirmam que Ramón Castilla foi considerado o libertador dos afro-peruanos, sendo que sua intensão ao decretar a abolição era recrutar soldados para seu exército na luta contra Rufino Echenique o presidente. Segundo os autores, essa visão dos fatos colabora para o apagamento das lutas e conquistas de 
liberdade do povo afro-peruano, pois, em 1854 o número de libertos por seu próprio esforço, já era maior do que os libertos pelo decreto de Castilla.

Além da cultura e sua própria história, as pessoas negras nas américas sofreram um forte processo de apagamento. Ainda, valoriza-se pouco os feitos dos homens negros e em especial das mulheres negras para a construção de seus respectivos países. Isso se dá pelo que Crenshaw (2004) chama de discriminação intersecional, ou seja, quando diferentes formas discriminatórias operam juntas sob um mesmo grupo social. Por isso, hoje tenta-se resgatar especialmente os feitos das mulheres afro-latinas, pois, se ouvir as vozes do Sul não é uma prática histórica, menos praticável ainda tem sido considerar as vozes negras femininas da América Latina, uma vez que constituem a base da pirâmide socioeconômica, sofrendo, portanto, a discriminação de raça, gênero e classe.

Molina e López (2018) destacam a importância das afro-argentinas em batalhas mesmo lutando ao lado do exército nacional, da qual apenas se sabe com certeza o nome de María Remedios del Valle, porém os autores defendem que havia a presença de muitas outras. Já no Peru, Lobatón e Julca (2018), afirmam que a presença da mulher afro-peruana, embora diminuída pela sociedade tem sido valorizada e resgatada nos últimos anos. Os autores destacam o trabalho de Victoria Santa Cruz na pesquisa cultural e de María Elena Moyano como dirigente popular.

No Brasil, muitas mulheres negras têm se tornado símbolo de luta e resistência e suas contribuições para a construção do país tem ganhado reconhecimento. Podemos citar Dandara dos Palmares como líder quilombola, Conceição Evaristo como escritora e, mais recentemente, Marielle Franco como representante política. Essa revisitação da história e acontecimentos faz reverberar as vozes que compõem a perspectiva afrogênica, e é também uma forma decolonial de entender as sociedades da América Latina, como o Brasil.

Apresentamos até aqui a relação entre a LA e os estudos decoloniais, demonstramos como a colonialidade segue presente na América Latina e resgatamos um pouco sobre o samba no Brasil como parte de um processo colonial. Em seguida, analisamos o samba-enredo 2019 de duas escolas de samba do Rio de Janeiro, que mostram como no carnaval está presente a mescla de discursos entre a história oficial e a perspectiva da população negra e demais povos subalternizados que se colocam como principais construtores desse legado cultural.

\section{SAMBAS-ENREDO 2019: ViLA ISABEL E MANGUEIRA POR UMA PERSPECTIVA AFROGÊNICA}

No carnaval do ano de 2019, quatorze escolas de samba desfilaram pela Liga Independente das Escolas de Samba do Grupo Especial do Rio de Janeiro (LIESA), no Sambódromo da Marquês de Sapucaí, também conhecido como Sambódromo do Rio de Janeiro e que possui como nome oficial 
Passarela Professor Darcy Ribeiro. Muito antes dos dias dos desfiles, que em 2019 ocorreram entre 1 e 9 de março e do Grupo Especial nos dias 3 e 4 de março, iniciam os preparativos para a festa, incluindo a escolha dos sambas-enredo como um dos quesitos mais importantes.

Nesse artigo, apresentaremos a análise de dois dos sambas-enredo de 2019, o do Grêmio Recreativo Escola de Samba Unidos de Vila Isabel e o do Grêmio Recreativo Escola de Samba Estação Primeira de Mangueira, popularmente conhecidos como Vila Isabel e Mangueira. Essas duas escolas foram escolhidas por, em seus sambas-enredo, tocarem na temática da história colonial do Brasil, que terão sua materialidade linguística analisada sob um viés decolonial, nos entramados que os usos da linguagem apresentam. O samba-enredo da Vila Isabel, é intitulado 'Em Nome do Pai, do Filho e dos Santos, a Vila Canta a Cidade de Pedro' ${ }^{6}$ e o da Mangueira é intitulado 'História pra ninar gente grande'?

O samba-enredo da Vila Isabel, 'Em Nome do Pai, do Filho e dos Santos, a Vila Canta a Cidade de Pedro', remete a um Brasil da época colonial, exaltando figuras históricas, como o Imperador Dom Pedro II, a princesa Isabel e seus herdeiros. Conta o legado da cidade de Petrópolis, construída por imigrantes e consagrada como cidade imperial, como pode-se verificar em sua letra, abaixo:

\section{Quadro 1 - Samba-enredo da Vila Isabel}

Vila
Te empresto meu nome
Fonte de tanta nobreza
Por Deus e todos os santos
Honre a tua grandeza
E subindo pertinho do céu
A névoa formava um véu
Lembrei de meu pai, minha fortaleza
Esculpida em pedras, Pedros
Terra dos Coroados
Os seus guardiões
Protetores de raro esplendor
Nas flores e estrelas
Nas cores e sons
Luar do imperador
Meu olhar lacrimejou

${ }^{6}$ Autores do enredo: Edson Pereira, Clark Mangabeira e Victor Marques, compositores: André Diniz, Evandro Bocão, Professor Wladimir, Júlio Alves, Marcelo Valência, Dedé Augusto e Ivan Ribeiro, intérprete: Anderson dos Santos (Tinga) e carnavalesco: Edson Pereira.

${ }^{7}$ Autor do enredo e carnavalesco: Leandro Vieira, compositores: Deivid Domênico, Tomaz Miranda, Mama, Marcio Bola, Ronie Oliveira e Danilo Firmino e intérprete: Marquinho Art'Samba. 


\begin{tabular}{|l|l|}
\hline Em águas tão cristalinas & Ecoa meu samba no alto da serra \\
Uma cidade divina & Na passarela com os herdeiros de Isabel \\
Bordada em nobre metal & \\
A jóia imperial & \\
\hline
\end{tabular}

Fonte: http://www.galeriadosamba.com.br/escolas-de-samba/unidos-de-vila-isabel/2019/ Acesso em: 15 nov. 19.

A história que é escolhida para ser contada parte de uma visão eurocêntrica, na qual a cidade de Petrópolis é vista como “A jóia imperial” e assemelha-se à Versalhes, cidade francesa na qual está situado o Palácio de Versalhes, castelo real da França. A colonialidade do poder se apresenta a partir da visão de que o que se assemelha ao europeu, no caso à França, é superior e digno de ser "Fonte de tanta nobreza" e, consequentemente, “Adorna a imensidão", apresentando uma subserviência ao legado histórico da época colonial.

Outro ponto no samba-enredo que remete à colonialidade do poder é a menção ao dia histórico da abolição da escravatura, em: "No Baile de Cristal o tom foi redentor/ Em noite imortal/ Fiz nascer um novo dia/ Liberdade enfim raiou”. A liberdade seria a dos escravos, remetendo à Lei Áurea, assinada em 13 de maio de 1888 e, posteriormente, ocorre a exaltação da princesa Isabel, em: "Viva a princesa,/ O tambor que se não cala/ E o canto do povo mais fiel/ Ecoa meu samba no alto da serra/ Na passarela com os herdeiros de Isabel”. Não se leva em consideração todo o processo histórico ocorrido para que se culminasse na assinatura da Lei Áurea e a única pessoa exaltada nesse processo é a princesa Isabel, indicando uma visão de subserviência à figura que somente assinou a Lei. A sinopse do enredo ${ }^{8}$ apresenta:

Que rufem os bumbos! No repicar dos tamborins, pede passagem a Branco e Azul cuja força provém do samba, eterna nossa tradição! É a comunidade que vem resgatar o império da Coroa do nosso pavilhão, herança da Isabel princesa, marca da nossa história gloriosa de emoção! Bate forte a bateria para marcar o tempo, o tempo novo da majestade Vila Isabel, o tempo de exaltar a nossa Coroa, na festa do povo, celebrando os corações do bairro de Noel, encontrando-se com outra Coroa, a da Casa Real, destinada a criar uma Cidade Imperial.

Segundo Gomes (2017), muitas são as críticas à abolição, mas não é possível negar que foi fruto de "um processo e a culminância oficial da emancipação do corpo negro como escravizado para o corpo liberto" (2017, p. 102). Tal emancipação significou uma ruptura política, social e econômica, entretanto foram entregues à própria sorte, sem condições mínimas de viver dignamente. O sambaenredo analisado, ao apresentar a princesa Isabel como única protagonista desse processo, invisibiliza toda a participação desses mesmos corpos negros:

\footnotetext{
${ }^{8}$ Disponível em: http://www.galeriadosamba.com.br/escolas-de-samba/unidos-de-vila-isabel/2019/ Acesso em 15/11/19.
} 
[...] a luta pela emancipação do corpo negro sempre foi uma presença marcante na vida e nas ações dos africanos escravizados e seus descendentes. As lutas, as rebeliões na senzalas, as lutas quilombolas, os abortos, os envenenamentos foram respostas fortes das africanas e africanos escravizados ao regime da escravidão. E em todas elas o corpo negro regulado pela escravidão se mostrava rebelde e lutava pela sua emancipação. Também hoje a história já nos revela que negros libertos também participaram do movimento abolicionista e não somente a classe média branca mais revolucionária da época (GOMES, 2017, p. 102).

Dessa maneira, a perspectiva eurogênica é a que está presente no samba-enredo analisado, pois é apresentada uma narrativa eurocentrada, cunhada nas colonialidades do poder, do ser, do saber e da linguagem, dando ênfase à exaltação da Coroa portuguesa, em nome da princesa Isabel, apontada como uma história gloriosa. Não é apresentado um olhar de dentro, dos povos que foram silenciados e dominados, sobrepondo, assim, a visão de mundo eurogênica, como forma de ser, saber e pensar o mundo.

O samba-enredo da Mangueira, 'História pra ninar gente grande', remete também ao período colonial do Brasil, entretanto realiza críticas à história oficial e exalta figuras que não costumam ter destaque nesse processo, como pode-se verificar em sua letra, abaixo:

\section{Quadro 2 - Samba-enredo da Mangueira}

Brasil, meu nego
Deixa eu te contar
A história que a história não conta
O avesso do mesmo lugar
Na luta é que a gente se encontra

Brasil, meu dengo a Mangueira chegou

Com versos que o livro apagou

Desde 1500 tem mais invasão do que

descobrimento

Tem sangue retinto pisado

Atrás do herói emoldurado

Mulheres, tamoios, mulatos

Eu quero um país que não está no retrato

Brasil, o teu nome é Dandara

Tua cara é de cariri

Não veio do céu

Nem das mãos de Isabel

A liberdade é um dragão no mar de Aracati

\author{
Salve os caboclos de julho \\ Quem foi de aço nos anos de chumbo \\ Brasil, chegou a vez de ouvir as Marias, \\ Mahins, Marielles, Malês \\ Mangueira, tira a poeira dos porões \\ Ô, abre alas pros teus heróis de barracões \\ Dos Brasis que se faz um país de Lecis, \\ Jamelões \\ (São verde-e-rosas as multidões) \\ Mangueira, tira a poeira dos porões \\ Ô, abre alas pros teus heróis de barracões \\ Dos Brasis que se faz um país de Lecis, \\ Jamelões
}

Fonte: http://www.galeriadosamba.com.br/escolas-de-samba/estacao-primeira-de-mangueira/2019/

Acesso em: 15 nov. 19. 
Ao optar por "a história que a história não conta”, o samba-enredo constrói uma outra história, que muitas vezes, não aparece nos espaços de poder, como os documentos, a televisão, as escolas, os livros didáticos, como é indicado em: "Brasil, meu dengo a Mangueira chegou/ Com versos que o livro apagou/ Desde 1500 tem mais invasão do que descobrimento”. É dada preferência ao vocábulo invasão em contraposição à descobrimento, indicando que aqui já existiam povos originários e que os europeus, na realidade, invadiram o continente.

A figura do herói oficial é rebaixada, denunciado através do símbolo do sangue das pessoas que foram escravizadas e mortas: "Tem sangue retinto pisado/ Atrás do herói emoldurado/ Mulheres, tamoios, mulatos/ Eu quero um país que não está no retrato”. A história do país que não está no retrato é a que foi apagada sobre as lutas travadas por negros e indígenas ao longo do tempo, em especial, das mulheres, que refletem as raízes da história.

Algumas dessas pessoas heroicas são retomados na letra, como Dandara, esposa de Zumbi dos Palmares, que teve liderança no quilombo dos Palmares e que se suicidou para não voltar a ser escravizada. Outra é a referência a Mahins, Luiza Mahin, também importante liderança de movimentos anti-escravagistas na Bahia. Também são feitas referências atuais, como Marielles, Marielle Franco, vereadora do Rio de Janeiro, que foi assassinada a tiros em 2018 e que defendia causas sociais, os direitos humanos e fazia fortes denúncias a casos de abuso de autoridade em comunidades carentes por parte de policiais.

Percebe-se que o samba-enredo busca por mulheres e homens que foram protagonistas na história do Brasil, seja na luta pela liberdade de pessoas escravizadas, seja na luta mais atual, pelos direitos humanos. Ao apontar que "Brasil, o teu nome é Dandara/ Tua cara é de cariri/ Não veio do céu/ Nem das mãos de Isabel/ A liberdade é um dragão no mar de Aracati", a história oficial é contraposta à não oficial, no momento em que coloca Dandara como símbolo do Brasil e diz que não veio das mãos de Isabel, a princesa da história oficial, mas relaciona a liberdade ao dragão do mar de Aracati, que é Francisco José do Nascimento, o Chico de Matilde, um símbolo da luta abolicionista cearense. Segundo a sinopse do enredo:

Ao dizer que o Brasil foi descoberto e não dominado e saqueado; ao dar contorno heroico aos feitos que, na realidade, roubaram o protagonismo do povo brasileiro; ao selecionar heróis "dignos" de serem eternizados em forma de estátuas; ao propagar o mito do povo pacífico, ensinando que as conquistas são fruto da concessão de uma "princesa" e não do resultado de muitas lutas, conta-se uma história na qual as páginas escolhidas o ninam na infância para que, quando gente grande, você continue em sono profundo 9 .

\footnotetext{
9 Disponível em: http://www.galeriadosamba.com.br/escolas-de-samba/estacao-primeira-de-mangueira/2019/ Acesso
} em: 15 nov. 19. 
Nesse trecho, é explicado o título do samba-enredo, 'História pra ninar gente grande', proveniente das histórias que nos foram contadas desde que somos crianças, desde as páginas dos livros da escola, como uma canção de ninar, e que ao nos tornarmos adultos, continuam povoando nosso imaginário de como ocorreram os fatos ao longo da história. Não nos é apresentado o outro lado, o das pessoas que lutaram bravamente contra os heróis encontrados nos livros e que tiveram protagonismo nas diversas lutas que ocorreram, dessa maneira, o ninar da infância transforma-se em um sono profundo na fase adulta, pois os livros que lemos nos ninaram e não nos ensinaram. Gomes (2017), ao discorrer sobre o movimento negro como educador, aponta sobre o papel da escola e dos livros didáticos em relação às comemorações cívicas sobre a questão do negro, como o 13 de maio, dia da assinatura da Lei Áurea:

A escola era a instituição em que tal interpretação era mais adotada. Geralmente, nas comemorações escolares, as crianças negras eram fantasiadas de africanos escravizados e uma menina branca e, de preferência, loura, era escolhida para representar a Princesa Isabel. Os manuais didáticos também apresentavam o 13 de maio como "o Dia da libertação dos Escravos" e nada se discutia sobre a luta e resistência negras, silenciando a participação dos negros na sua própria libertação (GOMES, 2017, p. 107).

Dessa maneira, na letra analisada, a perspectiva afrogênica ganha destaque, pois a história contada remete a visibilidade de pessoas comumente silenciadas nos discursos oficiais, e são apresentadas como os verdadeiros heróis conhecidos nas diversas lutas que foram travadas no processo de colonização e escravização. Embora os livros possam apagar essas histórias e muitas outras, o samba-enredo da Mangueira trouxe para o público algumas dessas pessoas, como uma maneira de enfrentar a colonialidade do saber, não negando mais os saberes locais e as histórias de grupos subalternizados. Entendemos que é imprescindível que para um olhar decolonial, os saberes desde dentro devem possuir protagonismo, de maneira a sulear nossas epistemes.

\section{CONSIDERAÇÕES FINAIS}

Tomando como base as categorias eurogênica e afrogênica, foram analisados os sambasenredo das escolas de samba cariocas Vila Isabel e Mangueira. Os resultados apontam que as escolas de samba apresentaram enredos em categorias opostas: a eurogênica, no da Vila Isabel e a afrogênica, no da Mangueira, indicando que as versões das narrativas contadas podem produzir discursos de silenciamento ou visibilizar o passado histórico através da reafirmação das identidades étnico-raciais. 
Destacamos que no samba-enredo da escola Vila Isabel, são exaltados os feitos da Coroa portuguesa como exemplo de superioridade e grandeza, bem como, são exaltados os valores imperiais, como herança europeia, sinônimo de nobreza e da visão eurogênica presente no enredo. Não há espaço nesse samba para as vozes do Sul, já que a narrativa apenas se concentra em uma parte da história do Brasil, através da voz da princesa Isabel, elucidando o quanto a visão eurogênica implicou o apagamento dos representantes populares dessa história.

Já no samba-enredo da escola Mangueira, vemos em destaque as mulheres como agentes na construção do país, os (as) afro-brasileiros (as) e demais pessoas que lutaram por liberdade em diversos momentos da história como na colonização e na ditadura militar, além dos povos originários que foram os principais símbolos de resistência do que o enredo chama de invasão e não de descobrimento. A perspectiva afrogênica presente no enredo ressalta as vozes do Sul, e a colonização é mostrada nas suas diversas faces, ora enaltecendo os representantes populares, ora desvelando o quanto os heróis oficiais, também tiveram um papel negativo nessa história.

O samba da Mangueira ainda abre espaço para homenagear os "heróis de barracões" homens e mulheres, negros e negras, populares, que com seu saber artístico também são símbolo de luta e trabalho na construção de um Brasil, para além dos livros de história. Essa homenagem ressalta a importância dos saberes locais, que como vimos, em contextos colonizados tendem a ser invisibilizados, seja na história, na música ou quanto personalidades influentes. Assim, a perspectiva afrogênica faz com que esse samba não seja uma forma de adormecer gente grande, mas, como propõe Conceição Evaristo, seja uma forma de incomodá-los em seus sonhos injustos.

Buscamos neste artigo, demonstrar como versões opostas dos mesmos fatos vem sendo forjados ao longo da história e identificamos que isso se dá tanto pelos resquícios de colonialidade ainda presente no imaginário social, quanto pela percepção de setores populares da sociedade que não se viam representados nas versões oficiais e partem então para a investigação de suas próprias histórias. Essa busca de conhecimento desde dentro, caracteriza o que se entende por decolonialidade do saber, uma vez que não toma como verdade absoluta a visão eurogênica e busca outras formas de saber, como a da perspectiva afrogênica.

A área da Linguística Aplicada, através de perspectivas decoloniais pode contribuir com os estudos da linguagem através de análises que busquem a desconstrução das colonialidades do poder, do ser, do saber e da linguagem, entendendo como as categorias eurogênicas e afrogênicas, apesar de opostas, convivem muitas vezes nos mesmos espaços de circulação. No caso específico desse artigo, a circulação ocorre nos sambas-enredo analisados, que embora tenham sido lançados na mesma época, apresentam visões diferentes dos mesmos fatos históricos, indicando que as narrativas são permeadas por discursos marcados ideologicamente. 


\section{REFERÊNCIAS}

ABREU, Martha Campos. O império do Divino: festas religiosas e cultura popular no Rio de Janeiro 183-1900. 450 f. Tese (Doutorado em Hisptória) Universidade Estadual de Campinas, Campinas, 1996.

BERNARDINO-COSTA, Joaze; GROSFOGUEL, Ramón. Decolonialidade e perspectiva negra. Revista Sociedade e Estado, Brasília, v. 31, n. 1, p. 15-24, 2016.

BRASIL, Eric Nepomuceno. Carnavais atlânticos: cidadania e cultura negra no pós-abolição. Rio de janeiro e port-of-spain, trinidad (1838-1920). 2016. 338 f. Tese (Doutorado em História) Universidade Federal Fluminense, Niterói, 2016.

CASTRO-GOMES, Santiago. Decolonizar la universidad. La hybris del punto cero y el diálogo de saberes. In: CASTRO-GÓMEZ, S.; GROSFOGUEL, R. (org.) El giro decolonial: Reflexiones para una diversidad epistémica más allá del capitalismo global. Bogotá: Siglo del Hombre Editores, 2007. p. 9-24.

CRENSHAW, Kimberle W. A intersecionalidade na discriminação de raça e gênero. In: VV.AA. Cruzamento: raça e gênero. Brasília: Unifem, 2004. p. 7-16.

ESCOBAR, Arturo. Mundos y conocimientos de otro modo: el programa de investigación modernidad/colonialidad latinoamericano. Tabula Rasa, Bogotá n. 1, p. 51-86, 2003.

GOMES, Nilma Lino. O movimento negro educador: saberes construídos nas lutas por emancipação. Petrópolis/RJ: Vozes, 2017.

KLEIMAN, A. Agenda de pesquisa e ação em Linguística Aplicada: problematizações. In: MOITA LOPES, L. P. (org.) Linguística Aplicada na Modernidade Recente: Festschrift para Antonieta Celani. São Paulo: Parábola, 2013, p. 39-58.

LOBATÓN, Oswaldo Bilbao; JULCA, Newton Mori. Os afro-peruanos: retrospectiva e situação atual. In: WALKER, S. (org.) Conhecimento desde dentro: Os afro-sul-americanos falam de seus povos e suas histórias. Rio de Janeiro: Kitabu, 2018. p. 463-528.

MALDONADO-TORRES, Nelson. Sobre la colonialidad del ser: contribuciones al desarrollo de un concepto. In: CASTRO-GÓMEZ, S.; GROSFOGUEL. R. (org.) El giro decolonial: Reflexiones para una diversidad epistémica más allá del capitalismo global. Bogotá: Siglo del Hombre Editores, 2007. p. 127-168.

MOITA LOPES, Luiz Paulo. Uma linguística aplicada mestiça e ideológica. Interrogando o campo como linguista aplicado. In: MOITA LOPES, L. P. Por uma Lingüística Aplicada Indisciplinar. São Paulo: Parábola Editorial, 2006, p. 13-42.

MOLINA, Lucía Dominga; LÓPEZ, Mario Luis. Participação de africanos e afrodescendentes na identidade nacional argentina. Uma visão afrogênica. In: WALKER, S. (org.) Conhecimento desde dentro: Os afro-sul-americanos falam de seus povos e suas histórias. Rio de Janeiro: Kitabu, 2018. p. 107-162.

NOGUERA, Renato. Denegrindo a filosofia: o pensamento como coreografia de conceitos afroperspectivistas. Griot - Revista de Filosofia, Amargosa, v. 4, n. 2, p. 1-19, 2011.

OSHAI, Cristina Maria Arêda. Reescrevendo as próprias histórias na perspectiva afrogênica. Revista da ABPN, Uberlândia, v. 7, n. 15, p. 240-260, 2015. 
PENNYCOOK, Alastair. Uma lingüística aplicada transgressiva. In: MOITA LOPES, L. P. Por uma Lingüística Aplicada Indisciplinar. São Paulo: Parábola Editorial, 2006, p. 67-84.

QUIJANO, Aníbal. Colonialidad del poder y clasificación social. In: CASTRO-GÓMEZ, S.;

GROSFOGUEL, R. (org.) El giro decolonial: Reflexiones para una diversidad epistémica más allá del capitalismo global. Bogotá: Siglo del Hombre Editores, 2007. p. 93-126.

SILVA JÚNIOR, Antônio Carlos; MATOS, Doris Cristina Vicente da Silva. Linguística Aplicada e o SULear: práticas decoloniais na educação linguística em espanhol. Revista Interdisciplinar Sulear, UEMG, Ano 2, n. 2 (set./2019) Edição Especial Dossiê SULear.

VERONELLI, G. A. Sobre la colonialidad del lenguaje. Revista Universitas Humanística. Bogotá, n. 81, p. 33-58, 2015. Disponível em: https://doi.org/10.11144/Javeriana.uh81.scdl. Acesso em: 02 dez. 2019.

WALKER, Sheila. Conhecimento desde dentro: Os afro-sul-americanos falam de seus povos e suas histórias. Rio de Janeiro: Kitabu, 2018.

WALSH, Catherine. Interculturalidad y (de)colonialidad: Perspectivas críticas y políticas. Visão Global, Joaçaba, v. 15, n. 1-2, jan./dez. 2012. p. 61-74. 